\title{
DOUBLE TROUBLE
}

\section{Youth from violent families: easy victims of crime?}

\author{
Lezanne Leoschut \\ Centre for Justice and Crime Prevention \\ lezanne@ cjcp.org.za
}

Crime and violence are pervasive in South Africa, and children and young people in particular are exposed to

high rates of violence within their homes. This article demonstrates that exposure to family violence increases the vulnerability of young people to becoming victims of crime. Interventions are needed that aim to change behaviour within families, provide institutional support for children outside the home, and thus make a tangible difference to the lives of South African youth.

Y outh in South Africa are exposed to disturbingly high rates of violence within their families. Previous research studies investigating this phenomenon have, for the most part, centred on the psychological impact on children who witness violence against their mothers. Many of these studies have however failed to probe other forms of violence that typically occur in families and the consequences that these might hold for children and youth.

This article attempts to bridge this gap by drawing on the research findings of the first $\mathrm{N}$ ational Youth Victimisation Study conducted in 2005. ${ }^{1}$ It aims to shed light on the victimisation experiences of youth by exploring the links between exposure to violence within the family (both as direct victims and as witnesses) and criminal victimisation in the South African environment. ${ }^{2}$

\section{Methodology}

The victimisation survey final sample comprised 4,409 young people between the ages of 12 and 22 years, recruited from all nine provinces in South Africa. The sample frame was provided by Statistics South Africa 2001 census data, and the sample was stratified by province and race. The total population between the ages of 12 and 22 years was identified. Based on this, a sample of 333 enumerator areas (EAs) was randomly selected, with 13 households in each identified for interviews. The final data was weighted by province, race and gender, using the marginal totals drawn from the 2001 census. This was done to ensure the most accurate representation of the experiences of young people throughout South Africa.

Participants responded to a survey questionnaire exploring their exposure to, and experiences of, crime and violence in their homes, schools, and the broader communities in which they live. The particular crimes explored in this study included both:

- violent crimes such as robbery, assault, rape/ sexual assault and car hijackings; and

- property crimes such as theft of personal property and housebreakings.

The questionnaire was piloted at two sites in Gauteng, one rural and one urban. Following the pilot, minor revisions were made to the questionnaire. Respondents were specifically asked about their experiences in the 12 months preceding the study, in order to minimise recall limitations. 
The raw data was then captured using the Statistical Package for the Social Sciences (SPSS) and was analysed by means of frequencies and crosstabulations using chi-square statistical tests.

\section{Demographic profile of the sample}

Of those surveyed, the majority came from KwaZulu-N atal (23\%), G auteng (16\%), Eastern Cape (16\%) and Limpopo (14\%) (Figure 1).

Figure 1: Sample by province $(n=4,409)$

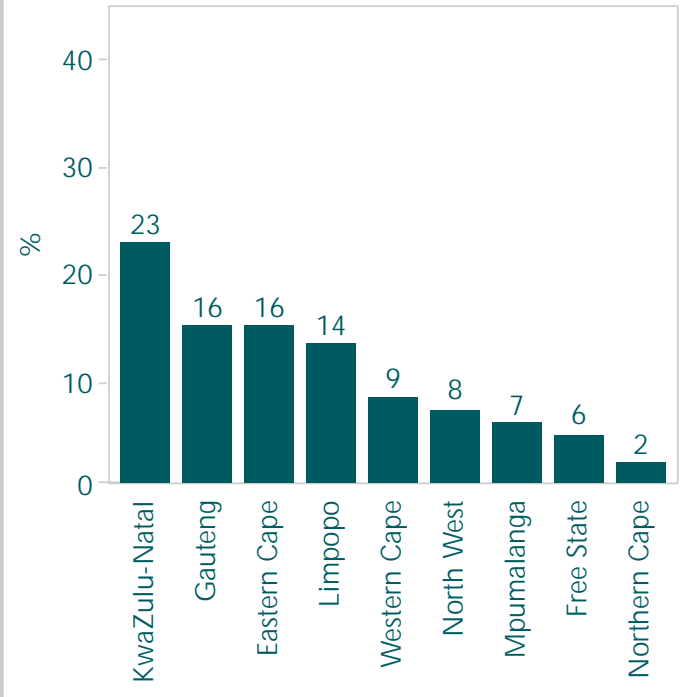

Female youth $(51 \%)$ and those between the ages of 15 and 20 years $(67 \%)$ constituted the greater part of the study sample. Black youth accounted for more than three quarters (83\%) of the respondents, while coloured $(8 \%)$, white $(7 \%)$ and Indian $(2 \%)$ participants constituted the remaining $17 \%$ of the sample. The sample consisted primarily of young people from rural areas ( $52 \%$ ) while few er respondents were recruited from urban (39\%) and metropolitan (9\%) areas (Figure 2).

At the time of the study, three quarters of the youth (76\%) were still attending school.

\section{Fear and loathing in the home}

South African society has been described as "very violent". ${ }^{3}$ Many of the youth surveyed were exposed to violence within their homes, both as witnesses and direct victims, indicating that this violence
Figure 2: Sample by area classification

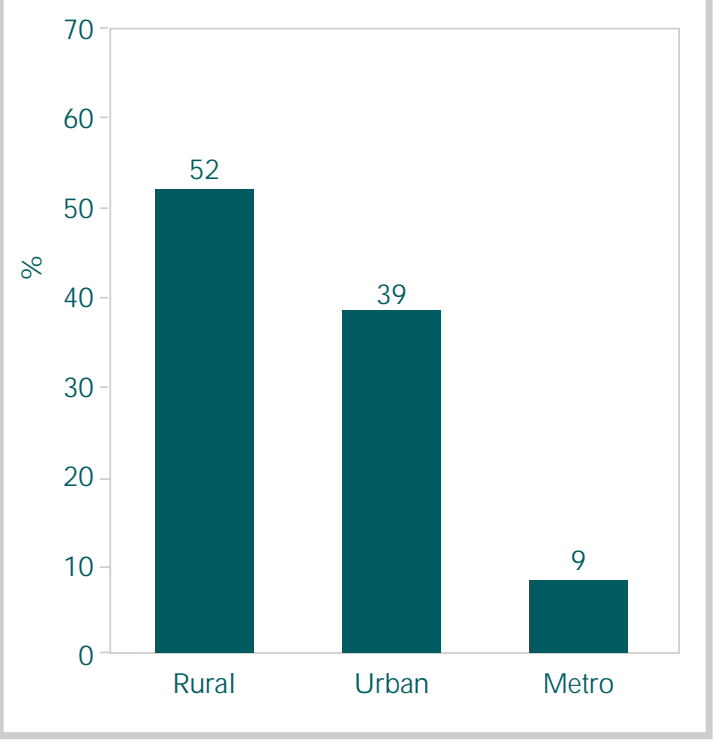

appears to have become entrenched in South African families.

More than a fifth $(22 \%)$ of the respondents had witnessed family members intentionally hurting one another (Figure 3). Of particular concern is the violent nature of these family disputes, since two fifths $(40 \%)$ of those who were exposed to domestic violence reported that a weapon had been used in the attack. Subsequently, more than a quarter (28\%) indicated that the victim in these disputes had sustained injuries as a result of the altercation. While exposure to family violence was common among youth from all provinces, it was found to be highest among those from the Northern Cape (33\%), N orth West (27\%), and Mpumalanga (26\%).

Arguments were also a common occurrence in the homes of these young people (Figure 3), and would often lead to physical altercations. O ne in ten (12\%) respondents indicated that their family members often became physical when they were angry with each other. These findings are again indicative of the violent nature of family arguments and the tendency to resort to physical violence in an attempt to resolve family conflicts.

When participants were asked at what age they first witnessed family members intentionally hurting 
Figure 3: Exposure among youth and children to family violence

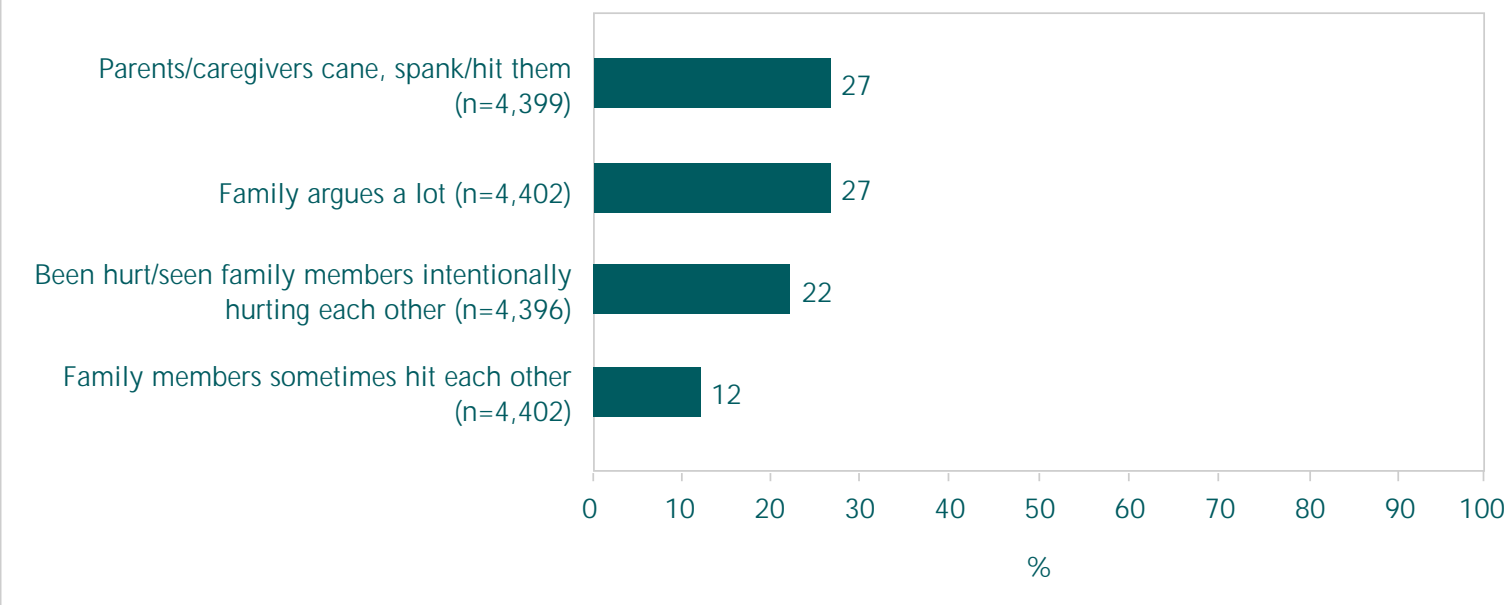

each other, nearly one in four (24\%) had first been a witness to family violence between the ages of 6 and 10 , while more than two fifths (46\%) were between 11 and 15 years (Figure 4).

These findings suggest that South African youth are often exposed to violence in their homes at an early age. And when children and young people are exposed to violence during their formative years, it impacts negatively on their developmental pathways. The physical and psychological

Figure 4: Age at which respondents first witnessed family violence

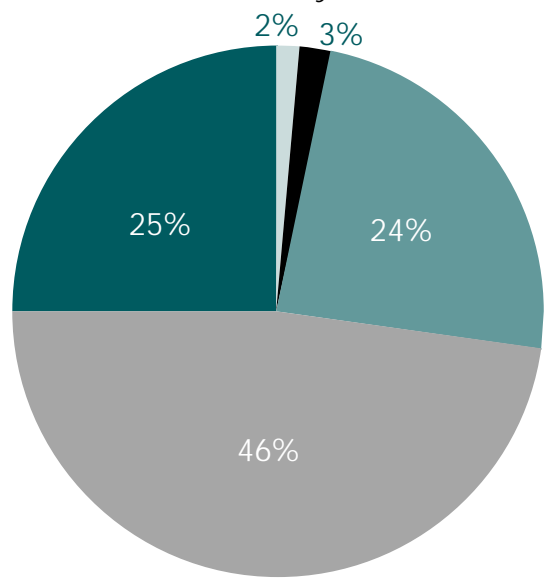

1-5 years

6-10 years

11-15 years

16-20 years

$<20$ years implications can be far-reaching: low self esteem, anxiety, depression, suicidal notions, and an increased likelihood of becoming involved with delinquent peers and activities. ${ }^{4}$ Youth who witness acts of violence in their homes are also more likely to encounter difficulties at school and often struggle to control their anger. ${ }^{5}$

Besides witnessing family violence, South African youth are also direct victims of violence in their homes. More than a quarter $(27 \%)$ of the young people surveyed reported that they had been caned, spanked or hit by their parents or caregivers for their wrongdoings. This study lends support to previous research studies that have found that even though corporal punishment has been abolished in schools, it continues to be a socially sanctioned means of effecting discipline within South African homes. ${ }^{6} \mathrm{G}$ irls (29\%) reported slightly higher rates of physical punishment than boys (26\%).

On the whole, these findings reflect the violent nature of the home environments in which many children and young people live. The legacy of apartheid has given rise to a situation in which many South African families consider physical violence as a socially acceptable means of problem-solving within the home. ${ }^{7}$ Thus, as evident in this study, violence in the home has become the norm rather than the exception for many youth in South Africa. 
This issue is of particular concern since young people are primarily socialised within the home. When their role models behave violently, these youth are likely to regard violence as an acceptable means of problem-solving, and employ these techniques when they need to resolve conflicts.

\section{Violence breeds vulnerability}

McCloskey, Figueredo and Koss maintain that youth who live in homes in which they are exposed to violence on a daily basis are more vulnerable than those not exposed to such a scenario, and hence are more likely to fall victim to crime. ${ }^{8}$ This tendency was also reflected in the National Youth Victimisation data. Young people who were raised in antagonistic households experienced higher rates of criminal victimisation than those not raised in such environments.

A statistically significant relationship was found between the participants who reported exposure to violence in their homes and those who had in fact been victimised. Respondents who reported that their families argued a lot, often lost their tempers, and became physical with one another when they were angry, reported significantly higher victimisation rates for most of the crimes explored in this study than those who were not exposed to such violence in their homes $(p<0.001)$. Those who witnessed family members intentionally hurting one another were also significantly more likely to have been criminally victimised.

Exposure to family violence not only makes young people more vulnerable to criminal victimisation, but also impacts on the number of victimisations that they are likely to experience. Young people who had experienced repeat victimisations were more likely to report exposure to violence within their families. These participants were more likely to report that their families argued a lot, often lost their tempers, and sometimes hit each other when they became angry.

There was also a strong relationship between physical punishment and repeat victimisations. The youth who reported that they were caned or spanked at home for their wrongdoings were more likely to report multiple victimisations than those who were not spanked. Even those who reported that they were only occasionally caned for their wrongdoings were more likely to report multiple victimisations than those who were not caned.

\section{Needed: non-violent families}

These findings were statistically very significant $(p=0.000)$, and suggest that young people who are exposed to various forms of family violence both as witnesses and direct victims are more vulnerable to criminal victimisation. Particularly concerning is that family violence exposure heightens the susceptibility of young people to violent crimes such as assaults and robberies.

The family is the primary socialising agent where children are taught about acceptable and unacceptable behaviour. Children who are continuously exposed to violence within the home, as is the case with the young people surveyed in this study, come to perceive violence as an appropriate means of conflict resolution and problem-solving technique. These findings point to the need for targeted interventions to raise awareness about appropriate conflict resolution techniques and alternative methods of discipline, particularly aimed at families since they constitute the primary role models for children and youth.

Youth who are victimised generally seek protection and support from their parents or other adults in their households. ${ }^{9}$ However, when domestic violence is a regular occurrence, as experienced by these young people, adult family members are unable to adequately meet the needs of these youth because they themselves are caught up in cycles of violence.

The subsequent lack of parental support is an issue of grave concern, because many South African youth do not have access to support systems outside of their families ${ }^{10}$ and thus rely on their parents/caregivers for emotional support following traumatic events. These findings thus call for the implementation of psycho-social support structures to be made available to youth outside of their homes, given the high rates of family violence in South Africa. 


\section{N eeded: safe spaces}

The data also suggest that South African youth have very few safe spaces where they are not at risk of being victimised. The widespread incidence of violence within these respondents' homes have serious implications for their psychological, physical and educational well-being. The creation of safe spaces for South African youth is a matter that needs urgent attention. The development of recreational and other social groupings and activities can provide these much needed safe spaces.

\section{Taking children's rights seriously}

Family violence exposure violates the rights of children to a life free from violence as stated in Article 19 of the Convention on the Rights of the Child (CRC), ${ }^{11}$ that protects children from all violence including physical and psychological forms of violence. ${ }^{12}$ In ratifying the Convention, South Africa has committed itself to ensuring the safety and well-being of all children in their homes and broader communities in which they live. According to the Convention, government parties are also responsible for ensuring that children are provided with the protection and care required for their well-being. However, this right has clearly been violated many times over.

These results are significant since they provide insight into one of the ways in which youth in South Africa are victimised. The study reveals the violent nature of the social environments in which many South African youth live and how this makes them more likely to experience criminal victimisation. How ever, a more comprehensive understanding of the factors influencing youth victimisation is crucial for advocating for more relevant and targeted youth policy that will reduce the specific threats facing South African youth.

\section{Endnotes}

1 L Leoschut \& P Burton, How Rich the Rewards: Results of the 2005 National Youth Victimisation Study, Cape Town, Centre for Justice and Crime Prevention, May 2006.

2 Unless indicated to the contrary in the text, the term 'family violence' is used here to denote all forms of violence involving members of the same family that usually occur in the home environment.
3 R Jewkes, J Levin \& L Penn-Kekana, Risk factors for domestic violence: Findings from a South African cross-sectional study, Social Science $\&$ Medicine 55 , pp. 1603-1617, 2002.

4 E Somer \& A Braunstein, Are Children Exposed to Interparental Violence being Psychologically M altreated? Aggression and Violent Behaviour, 4(4), pp. 449-456, 1999.

5 Ibid.

6 U Soneson, Ending Corporal Punishment of Children in South Africa, Save the Children Sweden, Pretoria, May 2005.

7 Jewkes, Levin \& Penn-Kekana, op cit.

8 LA M cCloskey, AJ Figueredo \& MP Koss, The Effects of Systemic Family Violence on Children's Mental Health, Child Development, 66, pp. 1239-1261, 1995.

9 RT Muller, AE Goebel-Fabbri, T Diamond \& D Dinklage, Social support and the relationship between family and community violence exposure and psychopathology among high risk adolescents, Child Abuse \& N eglect, 24(4), pp. 449-464, 2000.

10 Leoschut $\&$ Burton, op cit.

11 United Nations Convention on the Rights of the Child, O ffice of the High Commissioner for Human Rights, 2006, <http://www.unhchr.ch/html/menu3/b/k2crc. $\mathrm{htm}>$.

12 Soneson, op cit. 